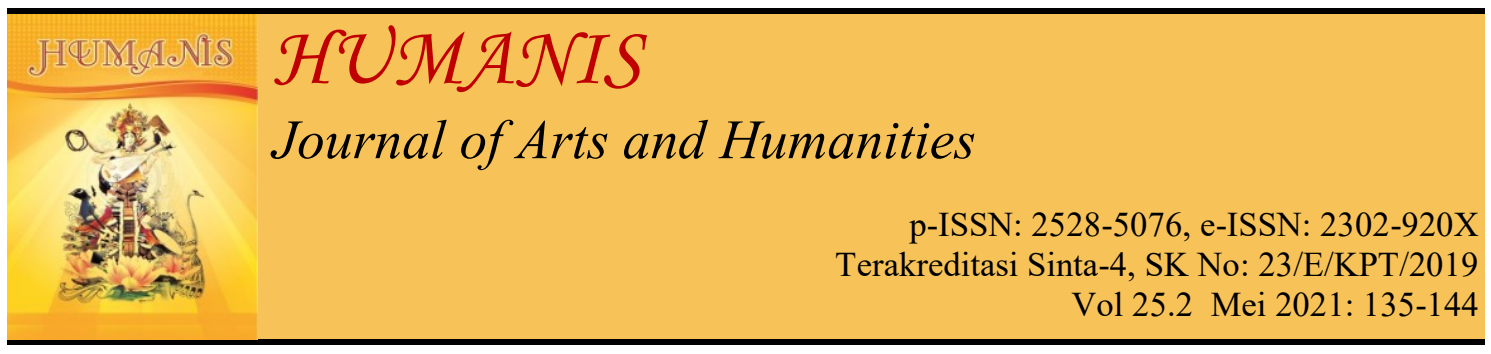

\title{
The Analysis of Semiotic Signs on Forest Fires' Posters
}

\author{
Desak Putu Eka Pratiwi, I Gusti Ayu Vina Widiadnya, Ni Luh Emi Puspita Sari \\ Universitas Mahasaraswati Denpasar, Denpasar, Bali, Indonesia \\ Correspondence email: desakekapratiwi@unmas.ac.id ; vina.ayu422@gmail.com ; \\ emipuspita8@gmail.com
}

\begin{tabular}{l}
\hline Article Info \\
\hline Submitted:19 $9^{\text {th }}$ February2021 \\
Revised: $6^{\text {th }}$ May 2021 \\
Accepted:11 $1^{\text {th }}$ May 2021 \\
Keywords: semiotic, verbal \\
sign, non-verbal sign, forest \\
fires, poster \\
Corresponding Author: \\
Desak Putu Eka Pratiwi \\
Email: \\
desak.eka.pratiwi@gmail.com \\
DOI: \\
https://doi.org/10.24843/JH.2 \\
021.v25.i02.p02 \\
\hline
\end{tabular}

\begin{abstract}
Forest fires are one of the global issues and need global concern. A campaign through forest fire posters on social media is a way to spread a message all over the world to prevent forest fires and save the earth from disaster. This study aims to discover the meaning of verbal and nonverbal signs used on forest fire posters. Verbal signs are about the text, either words or sentences while nonverbal signs are about pictures. The use of these two signs on a poster is meant to make people understand the message within it. The data were taken from three selected forest fire posters. The data were collected by observation method. The data were analyzed by a qualitative method using the theory of Semiotic by Barthes (1998) and supporting theory by Wierzbicka (1996). The finding shows that both verbal and nonverbal signs have important purposes such as giving some information about the impact of forest fires on nature and human life as well as warning people to be more responsible and aware of this global issue.
\end{abstract}

\section{INTRODUCTION}

Most people have been only aware of the language and do not realize that they also use signs in communication. The sign can be anything, it can be in the form of pictures, letters, numbers, songs, etc. According to Saussure in Yakin (2014), a sign is created from an idea of human minds which is expressed by language codes and comprehended by the people who are engaged in the conversation or communication. Communication itself can be divided into two types, verbal and non-verbal communication. Verbal communication is closely related to the language both oral or written that we use while nonverbal communication is more to communication that occurs through the meaning besides the word such as body language, gestures, pictures, colors, sound, etc.

Human beings use verbal communication as much as non-verbal communication. For example, verbal communication is used more during the meeting conference, work interview, or class discussion while non-verbal communication is more used in printing communication such as advertisement, pamphlet, or poster. According to Pucacicua (2014), the poster is a notice that consists of pictures and is displayed in public space. In the modern era, the poster is now not only used to promote a product but now it works as human 
artwork to deliver the aspiration of a group of people to influence society. For most people, the poster is the right media for them to deliver their concern towards any social situation and they use the poster to be part of their act to warn people of something, against a policy or persuade people to do what they should do. Posters are often used to support the campaign for climate change or environmental preservation.

Forests fires' posters are very attractive and not only filled with words but also many signs including colors, images, etc. Many groups of society take full concern on this matter and have carefully designed the posters to make their aspiration heard. Group of people who concern about forest fires competes to always attract the attention of society with full-color attractive posters. Many people make attractive posters and try to encourage people to follow their path in protecting the forest. This study specifically aims to analyze the meaning of verbal and nonverbal signs on forest fire posters. The semiotic approach is used to analyze the data of the study.

According to Saussure (1974), semiotics is a discipline that investigates the use of signs as a component of social life which is associated with logic. Theoretically, a sign is something that represents something or somebody in some respect or scope. Saussure declared that every thought is a sign. Anything can be a sign when someone assumes that it stands for something other than itself. It is this meaningful use of signs which is at the heart of the concerns of semiotics. Signs are more specific in the form of words, pictures, voices, smells, zest, actions, or objects; however, such things have no intrinsic meaning and become signs only when we imbue them with meaning Peirce in Chandler (2001: 16).

Posters consist of two signs, verbal and nonverbal signs. Verbal signs are about the text, either words or sentences, while nonverbal signs are about pictures. The use of these two signs in a poster is meant to make people understand the messages delivered by the producers. It is interesting to analyze the forest fire posters to help people discover the hidden message or values laid behind the verbal and nonverbal signs and to encourage people to support the campaign.

This topic was selected since it is very crucial to deliver a correct message in a correct way so the poster will be more effective and the values within the poster are well accepted by the readers. This research will be beneficial for the people or companies who create public service advertisements in form of the poster so they can design and produce more attractive posters with meaningful messages in them.

\section{METHOD AND THEORY}

The data in this research consist of three selected posters of forest fires campaign, such as (a) "Forest Fires Burn More than Trees"; (b) "Our Most Shameful Waste!"; and (c) "Save Amazon Rainforest's". The data were taken from several websites, such as dreamstime.com, amazon.com, and powerlibrary.org. The posters are about to warn of the current situation of the forest and the invitation to take care of the forest. The data were collected by observation method and note-taking technique. The researcher browsed and downloaded the data from the websites. Then, read and noted important information related to the topic of discussion. After that, the data were classified into verbal and nonverbal signs. The collected data were analyzed by a qualitative method using the theory of Semiotic proposed by Barthes (1998) and supported by other related theories. Semiotics is concerned with the depiction of signs, like language, image, and object. The visual signs have more 
forthright meaning than words. The depiction not only shows the world but also the interaction in it. It can be completed by words, sentences, text, or not. Then it will constitute a noticeable kind of text (paintings, posters, magazines, etc.) (Jewitt, 2004). The use of semiotics is getting broader when Barthes advanced the semiotics from linguistics to visual images, such as photography, advertisements, and motion picture. In conducting data analysis, the researcher analyzed and described the meaning of verbal and visual signs used in forest fires' posters. Then continued by analyzing the message within the forest fires' posters.

\section{RESULT AND DISCUSSION}

In analyzing signs, Barthes distinguished two parts of the sign that must be highlighted. He distinguished signs into two such as (a) verbal sign can be analyzed through text or in writing form. A poster usually consists of text in the form of the name or slogan, information about something, persuasion sentence, or any other form of text; (b) non-verbal sign can be in the form of color, music or sound, animation, or picture (Barthes, 1998). The non-verbal signs are used to support the verbal signs to make the posters more interesting.

In interpreting the signs, it occurs two levels of interpretation. The first level is a primer (denotation) and the secondary level develops into level metalanguage and connotation. Denotation exists when a sign is described authentically, actually, or based on dictionary definition (Chandler, 2007: 137). Barthes in Piliang (1999) stated that denotative is the relationship between signifier and signified which creates the direct and obvious meaning. According to Barthes in Krampen (1987: 80 ), the connotation is the "tone" of a text which has been decorated. Connotative is the signification level between signifier and signified which creates indirect and implicit meaning (Barthes, 1964: 91). Meanwhile, for Chandler (2007: 138), the connotation is "used to refer to the sociocultural and 'personal' associations (ideological, emotional, etc.) of the sign". The analysis of the meaning of verbal and nonverbal signs found on forest fire posters will be presented as follows.

\section{Data 1: "Forest Fires Burn More than Trees"}

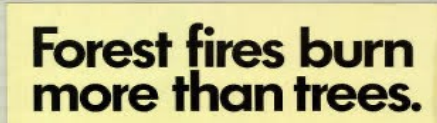

Figure 1. Forest fires burn more than trees poster from U.S. Government (Source:

http://psa.powerlibrary.org/cdm/ref/collection/ p/id/87)

\section{The Analysis of Verbal Signs}

The poster above was first published by the government of the United States in Google. This poster has a text as its verbal signs, "Forest fires burn more than trees". These verbal signs mean that forest fires not only burn trees but more than that. The author wanted the readers to know that forest fires are dangerous and deadly. Forest fires have a wider effect than what we can see. Forest fires increase carbon dioxide levels in the atmosphere which caused short and longterm health problems. Moreover, forest fires also cause flooding, landslides, the greenhouse effect, and climate change.

Forest is not only a place for trees but also for animals to live. If the forests got burnt, the animals will have no place 
to live, they will lose their habitat. Besides, many animals will die at the same time because of the fire itself. Even the baby animals who just started life will die immediately. Burning alive is one of the worst possible deaths. Animals that burnt to death experienced more pain than other animals dying in other ways. Not all animals caught in forest fires burn alive. Some of them die because of sniffing extremely hot smoke which probably pretty hurtful. It can be compared with a condition when people are burnt at the stake with big fires, they die because of asphyxiation rather than heat.

Hotter and drier situations are scorching ecosystems and advancing the endanger of wildfires. Wildfires also concurrently brunt weather and the climate by discharging huge loads of carbon dioxide, carbon monoxide, and fine particulate matter into the atmosphere. It results in air pollution which can create a number of health problems, including respiratory and cardiovascular. Another more serious health problem caused by wildfires is mental health or psychosocial well-being.

Those are some possible effects of forest fires on the animal, human being and nature itself. They are not explicitly mentioned on the poster to encourage the readers to think and be aware of the bad effect of the forest fires. It also persuades the readers to be more sensible and responsible for nature. Protect the forest also means protect the whole planet, so that all living things can live in a secure and healthy environment.

As stated by Barthes (1998) that signs consist of denotative and connotative 'levels of meanings', this poster tends to deliver the messages implicitly in which the messages are hidden and not clearly expressed on the poster. It is a technique to use words more efficiently and make the pictures speak more.

\section{The Analysis of Non-verbal Signs}

There are some non-verbal signs in the poster which support the verbal signs to deliver the message from the author to the readers. The first one is the background which is the important aspect of the poster. The author chose cream color as the background due to some reasons. Cream color represents the feeling of comfortable (Kemmis). Cream reflects the effect of neutral, calm, and relaxing. It represents the feeling of living in nature. In this case, the author implicitly tells the readers that if the forest was on fire, it will destroy the comfort zone of all creatures inside it.

The next signifier is the font color of the verbal utterance. The author chose a black color to point out the message. As the background of the poster is considered a light color, so the font color must be in dark color which in contrast with the background so the text will be more eye-catching and prominent. Therefore, the author chose a black color in order to attract the attention of the readers. Black color represents darkness, sadness, and death.

The last signifier is the image of a bird's nest. Birds represent the animal in the forest. This signifier is important to emphasize the message of the text above the image of the bird's nest. The text said, "Forest fires burn more than trees". So that by placing the image of a bird's nest below the text, it leads the readers to the idea that forest fires not only burn the trees but also all the living creatures that live in the forest, especially animals. It even causes a bigger disaster than anyone has ever imagined. It does not only endanger the existence of plants and animals in the forest but also gives a bad impact on the whole planet includes human beings.

Visual signs play an important role in an advertisement or a poster. It is quite difficult to attribute meaning to a short caption in a poster without a 
photograph. Pictures and colors can express a particular meaning which is hard to deliver in words. Further, the meanings that we do give to images are linked to culturally specific associations, though it is very necessary to note that culture cannot entirely determine our response (Potts, 1996: 31).

\section{Data 2: "Our Most Shameful Waste!"}

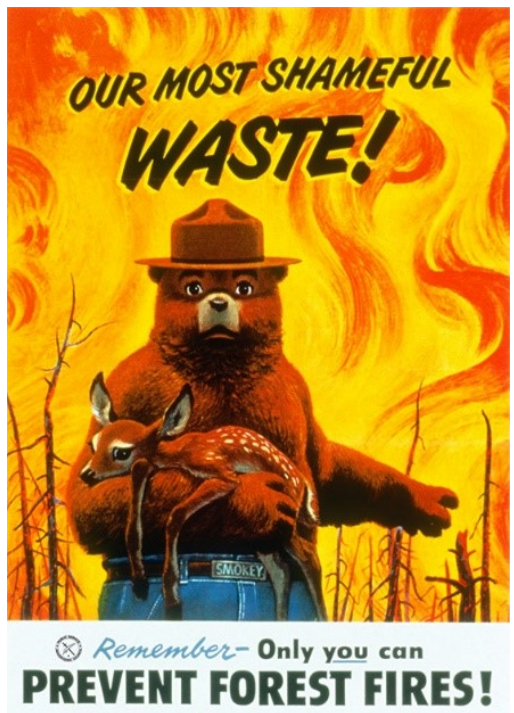

Figure 2. Our Most Shameful Waste's Poster (Source: https://www.amazon.com/SmokeyBear-Shameful-Vintage Poster/dp/B06XZG4R9K)

\section{The Analysis of Verbal Signs}

The first verbal sign is the text "Our most shameful waste!". This is a campaign that aims to raise patriotism. The meaning of this utterance is that the forest fire is such a waste of resources. We waste many things, we lost the lives of trees, animals, and even human beings. It should not happen if a human can do forest fire prevention. The author uses this campaign to express the feeling of disappointment for what humans did to the forest. It is a shame because we as human beings should be able to protect nature but in fact, many people just do not care about the forest. In addition, illegal deforestation also contributes to a forest fire. Legal deforestation ought to give benefits to human beings and not harm the forest. In fact, people are careless so that instead of getting benefits, we are wasting our resources.

The next text is written at the bottom of the poster. It is a kind of warning which aims to remind people to be more aware of the environment. The main message is that to awaken people that this is our responsibility to prevent forest fire since the forest is a vital aspect of human life which provides many natural resources for human needs. The sentence "Remember-Only you can prevent forest fire" is sending the message that it is only humans who can prevent wildfire. The word "you" is underlined to emphasize the importance of the subject who should do the action. The author invites all the readers to join the action of forest fire prevention. The author also used an exclamation mark at the end of the sentence to command people to do something and to show the urgency of this action.

It can be seen that the verbal signs have connotative meanings. Connotative meaning is the extended meaning of its denotative meaning. According to Barthes (1998) connotation works on a subjective level so the existence of the connotative meaning is unexpected. Connotation has a subjective meaning related to someone's emotion. Therefore, readers can interpret the messages within the poster differently.

\section{The Analysis of Non-verbal Signs}

The background in this poster is the fire and dead trees. This background represents that the fire is huge and can burn all things. The fire is all in red and orange color. The red color symbolizes blood and fire. Red is related to meanings of love, passion, desire, heat, strength, anger, danger, etc. Meanwhile, the color orange is seen as a very hot color. It usually brings the impression of heat. Orange is related to meanings of joy, 
warmth, heat, sunshine, etc. The color orange has very high visibility. So that it is usually used to get attention. It still gets your information seen without the bold. So that these colors are used as the background of the poster. Furthermore, there are pictures of trees which had been burnt with no leaves and all in black color. Black symbolizes power, fear, mystery, strength, death, evil, and aggression, authority, rebellion, etc. Black is needed for all other colors to create depth and variety of tone. It is categorized as a mysterious color which occasionally related to the unknown or the negativity. In this poster black implied death. While the trees represent all living creatures in the forest that died because of the fire. The background is generally sending a message to the readers that the forest and all living creatures inside it are terribly in danger and need help. Otherwise, all plants, animals, and other living things will die and it leads to a bigger disaster for human life. Generally, the background implicitly tells the readers about the effect of a forest fire so the readers can be aware and take action to prevent bigger disasters.

Another picture on the poster is a big bear pointing backward to the fire behind it. The bear is the representative of forest police in the USA which is named Smokey Bear. Smokey Bear is an American campaign and advertising figure of the U.S. Forest Service. Smokey Bear is employed to educate people about the risks of unplanned human-caused wildfires.

The bear holds a baby deer in his arms which looks very weak. It represents one of the victims of the forest fire. It implicitly shows that animals are suffered and died in the smoke and fire. Young and small animals are, particularly at risk. Heat can kill too, even organisms buried deep in the ground. Moreover, the majority of wildlife mortalities come after the fire is out, due to the loss of important habitat and food sources burned in the fire. The expression of the bear shows sadness, disappointment, and hope. A disappointment that this disaster happened and a hope that humans can do an action to overcome it. It is also a reminder for all human beings that "Only you can prevent forest fires", as the main message of this public service advertisement.

Visual signs are considered more explicit and straightforward in delivering the intended meaning than language itself. Visual signs have various meanings from culture to culture. Barthes (1998) called the immediate visual impact denoted meaning or basic meaning and the cultural meaning we attach to it connoted meaning or secondorder meaning. In conclusion, denoted meaning refers to the perception of what is registered by the picture, a picture of a monk for instance. Meanwhile, the connoted meaning refers to the possible invitation of the picture to interpret, give meaning to. In fact, the interpretation could even out of the authors' intention.

\section{Data 3: "Save Amazon Rainforests"}

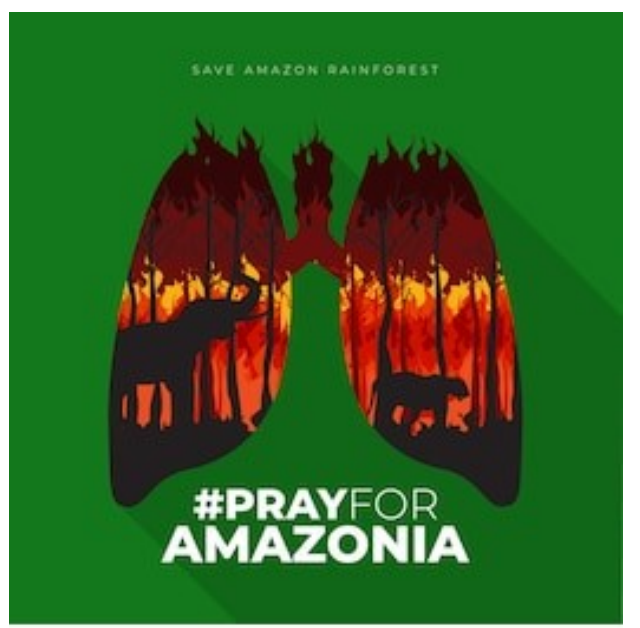

Figure 3. Save Amazon Rainforest's poster in Shutterstock (Source:

https://www.dreamstime.com/illustration/amaz onia.html) 


\section{The Verbal Signs Analysis}

The first signifier is the sentence "Save Amazon Rainforest". This is the campaign that has been announced by many environmental activists in Brazil. This campaign is announced louder during the forest fire incident in 2019 because according to INPE, the forest fire incident in 2019 has become the worst forest fire case that has ever happened in the history of Amazon. The Amazon fire in 2019 can be seen from the NASA satellite. The smoke covered almost all the atmosphere of Brazil and Paraguay during this event. The oxygen production is reduced and distracts the ecosystem. The Amazon is a "keystone ecosystem" which means that its health and prosperity are essentially related to the health and prosperity of the climate and planet. In brief, when the forest flourishes, so do the planet. When the forest is damaged, the planet is at risk.

This campaign is an invitation for the readers to save the Amazon rainforest that is currently burning. The author wanted to persuade everyone to stand up and do something to save the Amazon. This campaign is started with the word save which means to keep something from being destroyed. However, in this context, the word save is used to emphasize the actual purpose of the activists which is to rescue the forest so it can be inherited for the next generation.

Conserving this significant ecosystem is crucial since it has a rich biodiversity, giant carbon stocks, a role in climate settlement, and the position as the biggest surviving forest ecosystem on earth. Moreover, the Amazon is home to invaluable cultural diversity and to more than twenty-four million people, many of whom belong to indigenous communities. These groups are extremely affected by the ongoing fires, which are burning inside their areas and threatening their existence.
Another signifier is the sentence "\#PRAYFORAMAZONIA". It is found on Twitter as the media for this campaign. This online campaign used an imperative sentence as it persuades people to do action. The hashtag (\#) is used on Twitter to show particular topics/issues so it is easy to track anytime. A hashtag can also help people who share the same interest and same awareness about Amazon. If many people use the hashtag, it can be the trending topic on Twitter which means that the campaign has been spread widely. The advertiser wants to spread the campaign worldwide to get global attention since this is a very serious global issue. The Amazon rainforest works similarly like a super big sponge, absorbing and carrying the humidity that is blown in from the Atlantic. Once it is caught, each water molecule is recycled up to six times in the water cycle, being carried as rain and water condensation to the whole Amazon. Therefore, in that process, the rainforest makes its own rain, distributes it, and reuses it to preserve itself and to control the local climate. However, when the Amazon is burnt, the rainforest starts to lose its capability to trap and produce rain. As a result, it becomes drier which makes it frailer to fire. Based on that fact it is necessary to promote the campaign through social media which can reach out global audience to get more effective results. "\#PRAYFORAMAZONIA" is used to gain sympathy globally to raise people's awareness on this global issue and to motivate them to participate in protecting the Amazon rainforest.

The verbal signs in the poster above have both denotative and connotative meanings. According to Barthes (1998), denotation is the first order of signification. It refers to the simple or literal relationship of a sign to the references. Denotation meaning is also a common meaning which is accepted and 
approved in society. Barthes (1967: 91) defines connotation as the second order of signification. In the framework of Roland Barthes, the connotation is a sign which derives from the signifier of a denotative sign (so denotation leads to a chain of connotation).

\section{The Non-verbal Signs Analysis on Save Amazon Rainforest's Poster}

The first signifier is the background of the posters. There are two backgrounds that the author used. The first one is the green color. Green, the color of life, renewal, nature, and energy, is associated with meanings of growth, harmony, freshness, safety, fertility, and environment. The green color is used to represent the Amazon rainforest which symbolizes trees and nature. Green also brings with it a sense of hope, health, adventure. It all related to the atmosphere of the forest which is the source of life, hope, and adventure. Green is soothing, relaxing, and youthful.

Otherwise, the second signifier is the forest which is on fire. Red is dominating the background. Red, the color of blood and fire, is associated with meanings of love, passion, desire, heat, danger, stress, action, radiance, and determination. In this case, red closely associated with danger and emergency which represent the current condition of the Amazon rainforest in which the trees are all get burnt. There are also silhouettes of an elephant and a tiger which represent the wildlife inside the forest which are also in danger because of the fire. The elephant and tiger are the symbols of strong animals, but the fire makes them threatened and weak. As we can see the elephant's trunk is up as it is screaming for help. It can also be interpreted as the elephant is mad for seeing his home burnt down. The tiger is pictured to be powerless and walks away from the fire. It implicitly shows that forest fires are very dangerous and caused strong animals too weak which means the other animals could be even worse. It means that animals are in a critical situation.

The next one is a picture of the lungs. The reason why the author put lungs as the symbol of Amazon is that Amazon is known as the sole largest rainforest on earth which produce oxygen and store carbon dioxide. Lungs in the human body are an organ that distributes the oxygen and sends carbon dioxide out of human's body. So the author creates an analogy that the earth is the human body while the Amazon is the lungs. Lungs are a fundamental organ in the human body and so is Amazon as the earth's lungs. The author wants to let people know that the problem that happens in the Amazon rainforest is fundamental and must be fixed.

The next signifier is font style and font color. The sentences are all written in capital letters in order to grab people's attention. The capital letters are also used to emphasize that saving Amazon is an important thing and needs to be done quickly by all people in this world. Some of the words such as "Pray, Amazonia" are written in bold to attract people's attention and make them focus on the words. The color of the words is in white to support the message that by saving Amazon, the earth will be pure and peaceful which is represented by the color of white.

There is a solid tendency to consider visual signs as not a language, as uncoded and universal in their meaning. The aspects of visual signs do not have settled regulations, unlike words, which demand them to be arranged in certain modes to create a sign. In addition, visual signs and meanings are not tied as a dictionary links words with their signified. Visual signs are entwined with particular meanings, for instance, in the picture of Buddha, the meaning doesn't need different visual language. Or, the meanings of particular pictures can also 
be described in words, and consequently, we can comprehend various visual forms (Potts, 1996: 24-26).

\section{CONCLUSION}

Forest fires' poster is a way of public mass to raise awareness of society regarding the emergency situation that happens in the forest. The poster is posted widely through social media with the aim to reach a wide range of readers. The poster is designed as attractive as possible so it will reach a high impression from the readers. The essence of verbal signs in each poster is quite similar which is to warn people about forest fire issues and to persuade people to save the forest and prevent forest fires as well. On the other hand, the nonverbal signs on the posters are various and this made the posters unique and attractive. The non-verbal signs in all the posters consist of background colors, symbols, and images. Most of them exposed the picture of burnt forests and the animals as the victims. It dramatically attracts people's sympathy since it is breathtaking to see how the animals are suffering from the fires and burnt trees. Those pictures speak louder than words which are very effective to deliver the messages to the public that this is very urgent to take action to save the forest and save the world from bigger disasters. For the next researchers, it is recommended to analyze more various data related to nature conservation since there are a lot of advertisements or campaigns to educate the public about the importance of people's awareness in protecting this planet by using more attractive verbal and visual signs. So that, more people will aware that it is our responsibility to save the earth.

\section{REFERENCES}

Barthes, R. (1998). The Semiotics Challenge. New York: Hill and Wang.

Barthes, R. (2009). Mythologies. London: Vintage.

Barthes, R. (2007). Petualangan Semiologi. Yogyakarta: Pustaka Pelajar.

Chandler, D. (2000). Semiotics for Beginner. New York: Routledge.

Chandler, D. (2007). The Basic Semiotics. New York: Routledge.

Curtin, B., (2006). Semiotics and Visual Representations. [online] arch.chula.ac. Available at: $<$ http://www.arch.chula.ac.th/journ al/files/article/1JjpgMx2iiSun 10320 2.pdf $>$.

Jewitt, T. (2004). Visual Meaning: A Social Semiotic Approach. The Handbook of Visual Analysis, 9.

Krampen, M. (1987). Classics of Semiotics: Ferdinand de Saussure and the Development of Semiology. New York: Plenum Press.

Ogden, C. K., \& I. A. Richards. (1923). The Meaning of Meaning. London: Kagen Paul.

Piliang, Y. A. (2003). Hipersemiotika: Tafsir Cultural Studies Atas Matinya Makna. Yogyakarta: Jalasutra.

Potts, A. (1996). Sign in Robert S. Nelson and Richard Shiff, eds., Critical Terms for Art History. 
London and Chicago: University of Chicago Press.

Pucacicua, E. (2014). The Definition of Poster and The Example. Retrieved February 19, 2020, from slideshare.net/echapucacicua/thedefinition-of- poster-and-theexample.

Rifa'I, B. (2010). A Semiotic Analysis on Coca-Cola's Commercial Advertisements. Skripsi. Jakarta: English Letter Department, State Islamic University.

Saussure, F. (1988). Course in General Linguistics. Yogyakarta: Gadjahmada University Press.

Saussure, F. (1998). Pengantar Linguistik Umum. Penerjemah Rahayu S. Hidayat. Yogyakarta: Gadjahmada University Press.

Sulatra, I. K., \& Pratiwi, D.P.E. (2020). The Ideology within Covid-19 Public Service Advertisements: A Semiotic Approach. Jurnal Humanis, 24.4, 350-363.

Wierzbicka, A. (1996). Semantics Primes and Universals. New York: Oxford University Press.

Wishnawa, A.A.G.H., Sudipa, I. N., \& Sukarini, N.W. (2019). Semiotics Approach on Verbal Signs in Would You Care More IF I Was A Panda?. Jurnal Humanis, 25.1, 7177.

Yakin, H.S.M., Totu, A. (2014). The Semiotic Perspectives of Peirce and Saussure: A Brief Comparative Study. Retrieved October 15, 2019, from http://repo.uum.edu.my/12976/1/1s2.0.pdf.
Young, P.V. (1951). Scientific Social Survey and Research. New York: Prentice-Hall. 